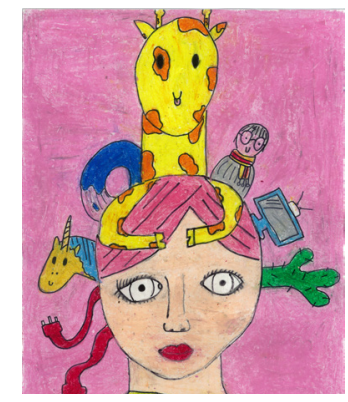

\title{
How Do Interprofessional Practice Teams Work Together to Identify and Provide for Gifted Students with Multiple Exceptionalities?
}

\author{
Jilly O'Brien, Tracy Riley, and Wendy Holley-Boen
}

\begin{abstract}
Priority learners in New Zealand include those who have special educational needs, yet gifted learners with multiple exceptionalities are variably identified, understood or provided for in our schools. International research advocates the use of interprofessional practice (IPP) teams, with competency across shared values, roles and responsibilities, communication, and teamwork, to support gifted learners with multiple exceptionalities. This study explored the experiences and understandings of IPP teams supporting students with multiple exceptionalities in New Zealand. The study found that IPP team identity is still in its infancy and core competencies are still evolving. Shared values towards inclusive practices were hampered by limited knowledge and expertise across the IPP team. Limited understandings of teamwork processes and limited recognition of the importance of communication within the IPP team were also common themes. Parents and students were typically not recognised as part of the IPP team identity and processes. The article concludes that gifted learners with multiple exceptionalities may not have adequate support at a systems level, and development of interprofessional practice competencies may be one way to ensure their full inclusion in our education system. Implications for policy and practice are described.
\end{abstract}

\section{Research paper}

\section{Keywords:}

gifted and talented education, gifted learners with multiple exceptionalities, inclusive education, interprofessional practice, twice exceptional

\section{SETTING THE SCENE: INTRODUCTION AND CONTEXT}

Gifted with a Learning Disability (GLD), Twice Exceptional, (2E), Gifted+, Gifted with Multiple Exceptionalities ... these are all terms used to describe a unique subset of gifted students: those who are gifted with one or more exceptionality. We use the term gifted with multiple exceptionalities, and by this we mean:
Gifted students whose performance is impaired, or high potential is masked, by one or more specific learning disabilities, physical impairments, disorders, or conditions. The difficulties inherent in turning potential into performance may necessitate support for positive socio-emotional affect, as well as support for learning (O'Brien, 2014, p. 3).

One of the defining characteristics of gifted students with multiple exceptionalities is the extreme asynchronous profile presented, what Tannenbaum and Baldwin (1983) describe as the 'paradoxical' learner. Gifted learners with multiple exceptionalities may display greater uneven development across developmental domains than other gifted children (Baum, Dann, Novak \& Preuss, 2009; Singer, 2000). It is the discrepancy between intellectual ability and performance (and often the efforts to mask this) that create the frustration, learned helplessness and negative self-affect common to this group of learners (Betts \& Neihart, 2010).

When the precocious perceptiveness and heightened sensitivity of the gifted child coexists with a debilitating learning difficulty, the stage is set for significant social and emotional dysfunction because the GLD student adopts a range of maladaptive perceptions and behaviours in the struggle against this perplexing condition (Hill, 2011 , p. 22).

Not surprisingly, gifted learners with multiple exceptionalities are considered a vulnerable school population (Hill, 2011; Silverman, 2007). If they are not recognised as a unique group of learners and offered teaching and learning strategies that meet both their academic and socio-emotional needs, the risk of underachievement is high and pervasive (Moon, 2002). Although inclusive education is the process by which schools transform themselves to meet the needs of all learners (UNESCO, 2005), gifted learners have often been outside of this shift as an underserved population in our schools (Tannenbaum, 2000). O'Brien's (2014) study sought to investigate, at a systems level, the interprofessional practice teams that may contribute to the inclusion of gifted learners with 
multiple exceptionalities in efforts towards fairness and equity in schooling.

Since 2005, New Zealand schools are required [as per National Administration Guideline (NAG) 1iii(c)] to identify students who have special needs (including gifted and talented), and to develop teaching and learning strategies to meet the needs of those students (Ministry of Education, 2012a). However, national studies have consistently found that while some positive change is evidenced, schools generally fail to adequately identify and provide for the needs of their gifted students (Education Review Office, 2008; Riley, Bevan-Brown, Bicknell, Carroll-Lind \& Kearney, 2004; Riley \& Bicknell, 2013). The Ministry of Education (2012b) recognise there are gaps in New Zealand research around the best way to meet the needs of gifted and talented students who have special needs, despite these students being identified as more vulnerable than either students with special needs or gifted students (Barber \& Mueller, 2011).

A successful approach undertaken overseas is one which is multidisciplinary - a collaborative taskforce able to take a multidimensional view, and individualise a plan for the gifted learner with multiple exceptionalities (Fetzer, 2000; Landrum, 2001; Nielsen, 2002; Rogers, 2010). This multidisciplinary approach has been adopted by some New Zealand schools under the guise of interprofessional practice. However, there is scant research on interprofessional practice for gifted learners with multiple exceptionalities. The study we report in this article, undertaken by O'Brien (2014), examines the interprofessional practice values of teams working to identify and provide for gifted learners with multiple exceptionalities.

\section{LITERATURE REVIEW: INTERPROFESSIONAL PRACTICE (IPP) TEAMS}

Interprofessional practice is "a highly integrated framework for collaboration among professionals" (Geva, Barsky \& Westernoff, 2000, p. 3). An IPP team is defined as two or more professionals working together towards a common goal, learning with, from, and about each other (Mentis, Kearney \& BevanBrown, 2012). IPP teams supporting gifted learners with multiple exceptionalities may include gifted and talented (G\&T) coordinators, guidance counsellors, health professionals, special needs coordinators (SENCO), parents/whanau, resource teachers of learning and behaviour (RTLB), and class teachers.

An interprofessional practice (IPP) team requires development of certain core competencies to be effective. According to the Interprofessional Education Collaborative Expert Panel (IPEC) (2011), these four competency domains consist of: values and ethics; roles and responsibilities; interprofessional communication, and team work. Developing effective teams with these competencies should create a more child-centred, effective, efficient, and equitable education for gifted learners with multiple exceptionalities. IPEC make it clear that how delivery occurs is as important as what delivery occurs, and this is particularly important for students who are gifted with multiple exceptionalities.

The literature highlights some aspects of IPP competencies and teams for gifted learners with multiple exceptionalities. For example, Rogers (2011) presented 11 strategies for what works in identifying gifted children with multiple exceptionalities in school districts in the US. Five of the 11 strategies are related to interprofessional practice, specifically the use of professional teams and their expertise. Literature also attests to the need for pre-service education and professional development opportunities across both gifted and special education paradigms, if these students are to be included and have their needs met in school (Kalbfleisch, 2013).

However, there have been limited publications in New Zealand literature that share knowledge of gifted learners interprofessionally. Cathcart (2002) urged RTLB to use their position to demystify giftedness. Blackett and Hermansson (2005) argued that developments in the mid-2000s in gifted education required a complementary response from school guidance counsellors; however, there had been no overall policy to bring this about, and counsellors have had to "respond as they see fit" (p. 281) with limited local research, no pre-service training, and few specialist providers. More recently, Hurst and Riley (2014) highlighted the need for more research exploring the multipotentiality of gifted learners in New Zealand to be undertaken by and for counsellors.

Based on the literature reviewed, and derived from the core competencies for interprofessional practice (IPEC, 2011), are several important research questions:

1. How do the differing values of various IPP team members fit with identification and provision for gifted learners with multiple exceptionalities?

2. What knowledge is there of roles and responsibilities within the IPP teams, and how much confidence is there to identify and provide for gifted learners with multiple exceptionalities?

3. What aspects of interprofessional communication assist, or do not assist, in identification and provision for gifted learners with multiple exceptionalities?

4. How does previous professional development in the area of teamwork (collaboration, consultation 
and communication, team roles, conflict resolution) affect identification and provision for gifted learners with multiple exceptionalities?

Delving into these questions gives researchers and practitioners an opportunity to explore and understand how things happen in interprofessional practice teams, and why they happen the way they do (Anderson, 1998). By looking at particular differences and similarities between interprofessional practice teams, general ways interprofessional practice teams work can be illuminated (Denscombe, 2003).

\section{METHODOLOGY}

O'Brien's (2014) research, reported in this article, used a qualitative case study methodology (Yin, 2014) to explore the practices of interprofessional practice teams, defined as two or more specialist personnel who have worked with one or more gifted learners with multiple exceptionalities over the last two years. Data collection techniques included an online questionnaire, complemented by follow-up email responses and interviews. Participation was invited through three websites that serve gifted and special needs educational communities in New Zealand: the Te Kete Ipurangi (TKI) Gifted and Talented Online listserv, giftEDnz: the Professional Association for Gifted Education's online newsletter; the NZ RTLB association, and the TKI online RTLB page.

Because case studies are often 'close up' qualitative accounts, they may be more intrusive and involve reactivity more than quantitative methods (Patton, 2002). Therefore, the research was assessed by our team under Massey University's code of ethical conduct, and through our discussions, it was deemed to be low risk (and this was confirmed by the Massey University Human Ethics Committee who accepted our review and notification).

Seven IPP teams agreed to participate in the online survey. Teams had between two and four members, were from rural and urban areas across the country, and were focused on a primary, intermediate or secondary age child. All teams indicated that their student was academically gifted with also autism spectrum disorder, attention deficit with hyperactivity disorder, specific learning difficulties, or cognitive processing difficulties. Whilst the study was open to other forms of giftedness and exceptionality, such as cultural giftedness, spiritual giftedness, or students with a physical disability, these were not evident in the teams that agreed to be in the study. Schools were private, state and state-integrated, and both single sex and co-educational.

The online questionnaire asked questions related to interprofessional practice core competencies such as: respondent attitudes to provision of, and access to, services for gifted students with multiple exceptionalities; knowledge of their and others roles and responsibilities; methods of communication and access to information, and information about specific skills in collaboration, consultation and conflict management. Of the seven respondent teams, three teams also agreed to be interviewed by phone, Skype or in person with as many team members as were available. The interviews took between 45 minutes to an hour. Open-ended questions from the survey were analysed for emerging themes, topics, threads, and contradictions. These themes formed the basis for the interviews, which were later analysed inductively and deductively. Themes were identified and refined within and across the transcripts, and then considered with reference to the interprofessional practice core competencies (IPEC, 2011). The study was mainly descriptive, exploratory, or revelatory, in that, to our knowledge, it was the first research completed on interprofessional practice teams and gifted learners with multiple exceptionalities, in New Zealand.

\section{FINDINGS AND DISCUSSION IN RELATION TO CORE COMPETENCIES}

Research findings were examined against the four competencies of interprofessional practice, namely: shared values and ethics; roles and responsibilities; communication, and teamwork.

\section{Shared Values and Ethics}

All IPP teams recognised that gifted learners with multiple exceptionalities require additional support, and on an equal footing with special needs learners. One team member noted, "I believed there was an acceptance that he wasn't going to fit the norm and there was a willingness to set up an individualised programme which is really the main step". Some, but not all, of the IPP teams espoused or enacted an understanding that the social and emotional needs of gifted learners with multiple exceptionalities were an important factor that must be addressed. A third of survey respondents thought performing at the norm academically was an indication that the gifted learner with multiple exceptionalities was being wellcatered for. Just over a third of the survey respondents either disagreed or did not know that gifted learners need challenge first, followed by accommodation strategies (such as reducing a written requirement), and remediation as the basic structure to their curriculum. These respondents had focused solely on remediation, which had not been successful in ameliorating behavioural problems or reducing anxiety.

In order for a team to work collaboratively around a student, shared values must develop within the interprofessional practice team, and there must be a 
culture of mutual respect (IPEC, 2011). Specifically, teams working with gifted students with multiple exceptionalities must share values about inclusive education as a process to meet the needs of diverse student populations, rather than being used as a synonym for special education (Kearney, 2013). Gifted learners with multiple exceptionalities require teaching strategies that focus on the strengths and interests of the child, rather than on what they cannot do (Betts \& Neihart, 2010; Olenchak \& Reis, 2002). By providing a teaching environment that fits the child in terms of their high ability, social and emotional problems and negative behaviours can be reduced significantly (Baum, Owen \& Oreck, 1996: Neihart, Reis, Robinson $\&$ Moon, 2002).

Findings suggest that there was a willingness amongst IPP teams to find a place for gifted learners with multiple exceptionalities within inclusive education. There was no support for Siegle and McCoach's (2005) findings that special education teachers (taken here as SENCO and RTLB) tend to have a negative view of the gifted - if anything, specialists in special needs education had an understanding and knowledge that contributed positively to understanding giftedness within inclusive education.

Inclusive values were not, however, shared comprehensively across and between IPP teams, and concerns were expressed that beliefs do not always translate into practice. Of greatest concern was the limited knowledge and understanding of the unique needs of gifted learners with multiple exceptionalities, in terms of classroom provision, social and emotional needs, variance in required day-to-day support, and evaluation of the support in terms other than academic scores. This means that these students may still not be experiencing inclusion, despite the positive intentions of support teams.

\section{Roles and Responsibilities}

Those from a special education background (RTLB, SENCO) tended to have received some formal training not only in special education, but also about gifted learners and gifted learners with multiple exceptionalities. This trend was not evident in the opposite direction. Gifted and talented coordinators typically had no formal training in special needs education or about gifted learners with multiple exceptionalities - and half had no formal training in gifted education either. IPP team members recognised that their own limited knowledge and the lack of knowledge within the IPP team affected the team's ability to meet the needs of gifted learners with multiple exceptionalities. Comments from team members illustrate their challenges in not having the skills and knowledge to define their roles and responsibilities:

"This whole $2 \mathrm{E}$ area is a minefield, and I have had to educate myself".

"I'm trying not to say I am flummoxed, but I am challenged because I have never worked with a $2 \mathrm{E}$ child before - in the normal course of events RTLB would be dealing with learning or behavioural problems".

"I have never had a child in my class with this label before".

This limited knowledge also impacted on the willingness of team members to take primary responsibility for the gifted learner with multiple exceptionalities. Most teams gave conflicting answers as to who had responsibility, with respondents rarely accepting the responsibility themselves, preferring instead to nominate someone else in the team or not nominate anyone. As one respondent said, "I don't think we named anyone for that, there was no one specific". Only one IPP team out of seven agreed on a shared responsibility. This may indicate limited coordination and teamwork within the IPP team, or limited confidence and knowledge to be the specialist key worker or stakeholder for the student.

In this study, most teaching strategies used for gifted students (e.g. activities for creativity, independent study, higher-order thinking, curriculum compacting, values education) were also recognised for gifted learners with multiple exceptionalities, but were not seen as portable to all students or students with special needs. Similarly, strategies recommended for special needs students (e.g. drill and practise, workbooks) were rarely recommended for gifted learners or gifted learners with multiple exceptionalities.

When professionals share their expertise in team situations, all members grow in confidence, expertise and understanding, and outcomes for students are positively impacted (Dettmer, Thurston, Knackendoffel \& Dyck, 2009). Being competent in your own role and responsibility area, and knowing the roles and responsibilities of other IPP team members, is a core competency for interprofessional practice (Suter, Arndt, Arthur, Parboosingh, Taylor \& Deutschlander, 2009). Being able to complement one another professionally is critical for childcentred educational provision. If team members lack individual expertise, this can limit the work of the whole team (IPEC, 2011).

Despite an ERO recommendation that school leaders should "promote specialist training and development for people specifically responsible for gifted and talented education" (ERO, 2008, p. 54), the findings 
of this research show a considerable lack of formal training in the area of gifted learners, with or without multiple exceptionalities. It would appear that the findings support the claim by Riley (2013) that gifted education teachers do not access inclusive research, policies and practice, and are becoming increasingly isolated. However, the findings do not support Riley's other claim that special needs educators do not access information and knowledge about gifted learners. Therefore, without clear team roles and responsibilities based on individual expertise, gifted education teachers and coordinators may inadvertently limit the work of the whole team by lacking individual expertise in their own area.

Baum, Owen and Dixon (1991) state that gifted learners with multiple exceptionalities are usually identified when parents or teachers suspect a problem. Parental involvement in identification is key, as they can provide insight not readily accessible to the teacher (Baum et al., 1991; Rivera, Murdock \& Sexton, 1995). Even though parents were involved in identification in all seven cases, they were only considered part of the team in two cases. In an inclusive process, the people most knowledgeable about the issue (the family and the student) would always be included.

\section{Communication}

Findings show that four of the IPP teams met regularly for identification and provision for gifted learners with multiple exceptionalities. The other three teams did not meet all together, face-to-face or virtually, at any stage of the process. Respondents indicated that either it was not necessary to meet as a full team, or that it was not possible to find time or space to do so. One class teacher explained that " ... to find that time was near on impossible, it meant three or four people had to do major juggles to make it happen. And if it's not easy it won't happen and won't happen regularly".

IPEC (2011) regard communication as a core aspect of interprofessional practice; team members must work towards a common understanding of the issue by expressing their individual knowledge and opinions to the team clearly, confidently and respectfully. BennettEmslie and McIntosh (1995) identify the single, mostimportant factor to foster collaborative teamwork is the frequency of team meetings, which enable more dialogue to occur between team members. Poorlyestablished dialogue can lead to deteriorations in service provision, because IPP team members do not iron out their differences enough through discussion to put the client in the centre (McCallin, 1999). For the three out of seven IPP teams who never met all together, this may indicate that teams have not communicated their readiness to work together
(Baggs \& Schmitt, 1997), or it may mean time and organisational factors made it impossible. Teams may need to use time- and place-saving communication tools and technologies if interprofessional practice is to be effective (IPEC, 2011). None of the IPP teams in this study used videoconferencing tools (e.g. Skype) in order to communicate, and we need to try to understand the challenges for professionals making use of technologies that could enhance team function by increasing the ease of communication.

\section{Teamwork}

In this research, some education professionals had received formal training in teamwork skills. Special needs educators (SENCO and RTLB) had received training in teamwork skills, and were recognised for using that expertise to get the team together, keep the team together, and lead a systematic process for the team to follow. Comments related to team work demonstrate the difference this background made to practice:

"The RTLB was good at being non-threatening and she did validate each person so they felt secure and able to contribute and she was highly skilled in that area".

"She (RTLB) facilitated the first meeting and she said who would do what and it was all colourcoded. She lets you know where she is up to and you're not left in the dark. It is all quite systematic".

In contrast, gifted and talented coordinators and class teachers had not received the same level of teamwork training. Respondents did not appear familiar with the concept of interprofessional practice teams, with three teams expressing the feeling that although they acted as a team, they probably would not have seen themselves as a discrete unit or called themselves a team. A culture of interprofessional practice teams was not yet evident. Teachers and gifted and talented coordinators noted:

"You keep using that word 'team' and my initial question was, 'what is this word team and what team are you talking about and who are these people?'"

"I have a close working relationship with my colleagues and I see us as working together, but I am realising through my conversations that maybe my colleagues don't! This is clearly an area for future development".

Teamwork is necessary in any setting where professionals have shared goals (IPEC, 2011). Teamwork relies on other key competencies of shared values: being clear about roles and responsibilities, and practising effective communication. Teamwork also requires specific training in what McCallin 
(2001) calls the concept of collectivity, the bigger picture, and citizenship skills. In the healthcare field, McCallin asserts that few professionals are taught these teamwork skills and thus they are not part of their professional identity.

A parallel may be drawn with education to assert that, similarly, few education professionals see teamwork skills as part of their professional identity. Hall (2005) asserts that teamwork skills do not always focus on communication across professions, and so individuals are prepared only to work within their own profession. In this research, it was clear that those education professionals who had been taught teamwork skills were able to use them across professions, and were recognised for using their expertise for the benefit of the team.

\section{IMPLICATIONS FOR POLICIES AND PRACTICES}

Implications for practice include developing interprofessional communication strategies (including growing digital competencies to increase the frequency and effectiveness of team meetings), interprofessional teamwork skills, interprofessional education, and reconceptualisation of IPP teams in ways that include students and families. Participants concurred with the research evidence that attests to the importance of frequent, targeted meetings that are genuinely collaborative and involve the whole team. This could be achieved through Individual Education Plan (IEP) processes set in motion as a matter of course and at the earliest opportunity for gifted learners with multiple exceptionalities. Further research is recommended on the benefits and barriers of using new technologies to enhance communication between the team, specifically in overcoming time and location constraints to be all together. Training in collaboration, consultation, communication, team roles and processes across disciplines rather than within them would be beneficial to developing effective teams, beginning at the pre-service stage. It is therefore recommended that interprofessional teamwork becomes an evidence-based competency for all professional appraisal schemes within the education sector.

Limited understandings of one's role, the area of specialisation and the roles of others on the team, function as major barriers to effective interprofessional practice. Formal and informal ongoing interprofessional education would enable all educators to have clear understandings of their own and others' expertise. Understanding and appreciating the expertise brought by the parent and student would enable effective identification and provision. Terminology matters, and a name change to Interprofessional Practice and Whānau (IPW) teams, may invite inclusion of all parties.

The limitations of this study are centred around the fact that the sample may not be representative of the range of diverse views and practices in IPP teams within the education sector. Not all education sectors were represented; for example, there was no data from early childhood or tertiary centres, or importantly from Kura Kaupapa Māori-medium schools. IPP teams may not represent a cross-section of all teams working with gifted students with multiple exceptionalities, as all teams in the study referred to academically gifted children, rather than a multicategorical approach to giftedness.

\section{FINAL THOUGHTS}

Interprofessional practice teams may be one way to support the paradigm shift to inclusive education within schools in Aotearoa/New Zealand. As McCallin (1999) states, potential difficulties with interprofessional teams can be overcome when a team adopts a client-focused, pluralistic, worldview. Teams therefore need to ask and answer the question 'what will it take for this child to succeed?' together, as an identified team, inclusive of the student and whānau. This will be an iterative process throughout the student's school life. Continuing development of interprofessional practice core competencies by all education professionals would appear vital for genuine inclusion of all diverse school populations, including gifted learners with multiple exceptionalities, within New Zealand schools. What is also critical is further empirical research on New Zealand-based practices showing the processes interprofessional practice teams use, and more importantly, whether their effectiveness improves outcomes for our students.

\section{REFERENCES}

Anderson, G. (1998). Fundamentals of educational research. London, England: Falmer Press.

Barber, C., \& Mueller, C.T. (2011). Social and selfperceptions of adolescents identified as gifted, learning disabled, and twice-exceptional. Roeper Review, 33(20), 109-120.

Baggs, J. G., \& Schmitt, M. H. (1997). Nurses' and resident physicians' perceptions of the process of collaboration in an MICU. Research in Nursing \& Health, 20(1), 71-80.

Baum, S., Owen, S. V., \& Dixon, J. (1991). To be gifted and learning disabled: From identification to practical intervention strategies. Melbourne, Australia: Hawker Brownlow Education. 
Baum, S. M., Owen, S. V., \& Oreck, B. A. (1996). Talent beyond words: Identification of potential talent in dance and music in elementary students. Gifted Child Quarterly, 40(2), 93-101.

Baum, S., Dann, M., Novak, C., \& Preuss, L. (2009). In their own stream: Managing dynamic asynchrony. Retrieved from:

http://www.2enewsletter.com/topic_articles_ myths_2.html

Bennett-Emslie, G., \& Mclntosh, J. (1995) Promoting collaboration in the primary care team - the role of the practice meeting. Journal of Interprofessional Care, 9(3), 251-256.

Betts, G., \& Neihart, M. (2010). Revised profiles of the gifted and talented. In 11th Asia Pacific Conference on Gifted, Sydney, Australia.

Blackett, J., \& Hermansson, G. L. (2005). Guidance and counselling of the gifted and talented in New Zealand. International Journal for the Advancement of Counselling, 27(2), 277-287.

Cathcart, R. (2002). The mystery condition. Detection and intervention. Retrieved from: http://www.giftedreach.org.nz/pdf/the_mystery_ condition.pdf

Denscombe, M. (2003). The good research guide (2nd ed.). Milton Keynes, England: Open University Press.

Dettmer, P., Thurston, L., Knackendoffel, A., \& Dyck, N. (2009). Collaboration, consultation, and teamwork for students with special needs. Boston, MA: Pearson Education.

Education Review Office (2008). Schools provisions for gifted and talented students. Wellington, NZ: Education Review Office.

Fetzer, E.A. (2000). The gifted/learning disabled child: A guide for teachers and parents. Gifted Child Today, 23(4), 44-50.

Geva, E., Barsky, A. E., \& Westernoff, F. (2000). Interprofessional practice with diverse populations: Cases in point. Westport, CN: Greenwood Publishing Group.

Hall, P. (2005). Interprofessional teamwork: Professional cultures as barriers. Journal of Interprofessional Care, 19(1), 188-196.

Hill, F. (2011). From GLD to gold. In C.Wormald \& W. Vialle (Eds.), Exceptionality, (pp. 21-30). Wollongong, Australia: AAEGT.

Hurst, N., \& Riley, T. (2014). Fruits of the fig tree: Counsellors' roles in assisting gifted and talented to address their multipotentiality. New Zealand Journal of Counselling, 34(1), 1-20.
Interprofessional Education Collaborative Expert Panel (2011). Core competencies for interprofessional collaborative practice: Report of an expert panel. Washington, D.C.: Interprofessional Education Collaborative.

Kalbfleisch, M.L. (2013). Twice exceptional students. IN C.M. Callahan \& H.L. Hertberg-Davis (Eds.), Fundamentals of gifted education: Considering multiple perspectives, (pp. 358-365). London: Routledge.

Kearney, A. (2013). Barriers to inclusive education: The identification and elimination of exclusion from and within school. In Centre of Excellence in Research in Inclusive Education, Massey University. Inclusive education perspectives on professional practice, (p. 40-51). Auckland, NZ: Dunmore Publishing.

Landrum, M. S. (2001). Resource consultation and collaboration in gifted education. Psychology in the Schools, 38(5), 457- 466.

McCallin, A.M. (1999). Pluralistic dialogue: A grounded theory of interdisciplinary practice. Australian Journal of Rehabilitation Counselling, 5(2), 78-85.

Mentis, M., Kearney, A., \& Bevan-Brown, J. (2012). Interprofessional learning and its contribution to inclusive education. In S. Carrington, \& J. MacArthur (Eds.), Teaching in inclusive school communities, (pp. 295 - 312). Brisbane, Australia: John Wiley \& Sons Ltd.

Ministry of Education (2012a). National administrative guidelines. Retrieved from: http://www.minedu.govt.nz/theMinistry/ EducationInNewZealand/EducationLegislation/ TheNationalAdministrationGuidelinesNAGs.aspx

Ministry of Education (2012b). Gifted and talented students - meeting their needs in New Zealand schools. Wellington, New Zealand: Learning Media.

Moon, S. (2002). Gifted children with attention deficit/hyperactivity disorder. In M. Neihart, S. Reis, N. Robinson, \& S. Moon (Eds.), The social and emotional development of gifted children: What do we know? (pp. 193-204). Waco, TX: Prufrock Press.

Neihart, M., Reis, S. M., Robinson, N. M., \& Moon, S. M. (2002). The social and emotional development of gifted children. What do we know? Washington, D.C.: Prufrock Press.

Nielsen, M.E. (2002). Gifted students with learning disabilities: Recommendations for identification and programming. Exceptionality: A Special Education Journal, 10(2), 93-111. 
O'Brien, J. (2014). How do interprofessional practice teams work together to identify and provide for gifted students with multiple exceptionalities? Master's thesis, Massey University, Albany, New Zealand. Retrieved from: http://mro.massey.ac.nz/handle/10179/6317.

Olenchak, F. R., \& Reis, S. M. (2002). Gifted students with learning disabilities. In M. Neihart, S. M. Reis, N. Robinson, \& S. Moon (Eds.), The Social and Emotional Development of Gifted Children (pp. 177-192). Waco TX: Prufrock Press.

Patton, M. Q. (2002). Qualitative research and evaluation methods (3rd ed.). Thousand Oaks, CA: Sage Publications.

Riley, T. (2013). Including gifted and talented students: Shifting our mindsets from exclusive to inclusive. In Centre of Excellence in Research in Inclusive Education, Massey University. Inclusive Education Perspectives on Professional Practice (pp. 189-204). Auckland, NZ: Dunmore Publishing.

Riley, T., Bevan-Brown, J., Bicknell, B., CarrollLind, J., \& Kearney, A. (2004). The extent, nature and effectiveness of planned approaches in New Zealand schools for identifying and providing for gifted and talented students. Wellington, NZ: Ministry of Education.

Riley, T., \& Bicknell, B. (2013). Gifted and talented education in New Zealand Schools: A decade later. APEX: The New Zealand Journal of Gifted Education, 18(1). Retrieved from: www.giftedchildren.org.nz/apex

Rivera, D.B., Murdock, J., \& Sexton, D. (1995). Serving the gifted/learning disabled. Gifted Child Today, 18(6), 34-37.

Rogers, K.B. (2010). Finding and supported twice exceptional learners in the primary grades: What works? In 11th Asia Pacific Conference on Gifted, Sydney, Australia.

Rogers, K.B. (2011). Thinking smart about twice exceptional learners: Steps for finding them and strategies for catering for them appropriately. In C. Wormald \& W. Vialle (Eds.), Dual exceptionality (pp. 57-70). Woollongong, Australia: AAEGT.

Siegle, D., \& McCoach, D.B. (2005). Making a difference: Motivating gifted students who are not achieving. Teaching Exceptional Children, 38(1), 22-27.

Silverman, L.K. (2007). What we have learned about gifted children: 1979-2007. Denver, CO: Gifted Development Center.
Singer, L. (2000). If Gifted = Asynchronous Development, then Gifted/Special Need = Asynchrony Squared. In K. Kay (Ed.), Uniquely gifted: Identifying and meeting the needs of twice exceptional students. Gilsum, NH: Avocus Publishing.

Suter, E., Arndt, J., Arthur, N., Parboosingh, J., Taylor, E., \& Deutschlander, S. (2009). Role understanding and effective communication as core competencies for collaborative practice. Journal of Interprofessional Care, 23(1), 41-51.

Tannenbaum, A.J., \& Baldwin, L.J. (1983). Giftedness and learning disability: A paradoxical combination. In L. H. Fox, L. Brody, \& D. Tobin (Eds.), Learning disabled gifted children: Identification and programming (pp.11-36). Baltimore, MD: University Park Press.

Tannenbaum, A. J. (2000). A history of giftedness in school and society. International handbook of giftedness and talent, 2, 23-53.

UNESCO (2005). Guidelines for inclusion. Retrieved from:

http://unesdoc.unesco.org images/0014/001402/140224e.pdf

Yin, R. K. (2014). Case study research: Design and methods (5th ed.). Thousand Oaks, CA: Sage.

\section{AUTHOR PROFILE}

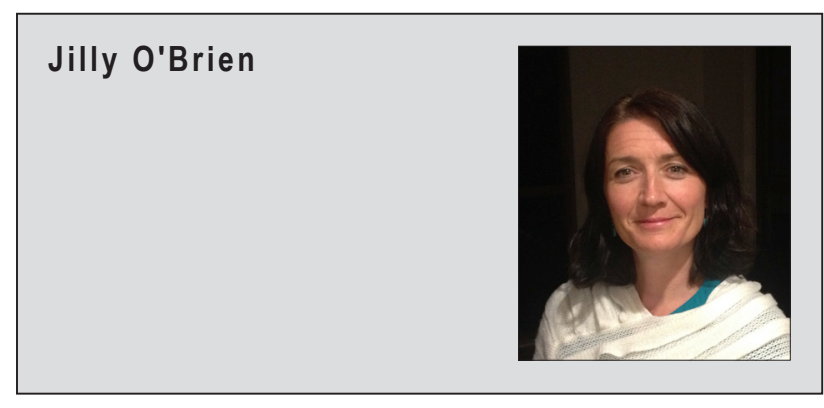

Jilly O'Brien works at the Ministry of Education, Special Education in Dunedin. She is currently completing the Educational Psychology internship programme at Massey University. Jilly has an interest in gifted learners with multiple exceptionalities, inclusion, and challenging behaviour (together and separately). Prior to this, she taught gifted children at primary and secondary level in Central Otago.

Email: obriensnz@gmail.com 


\section{Tracy Riley}

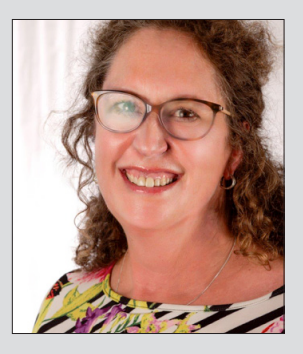

Tracy Riley is an associate professor in the Institute of Education at Massey University. She is passionate about the education of gifted and talented learners, of all sorts. Tracy is committed to the ongoing professional learning and development for those working with gifted and talented learners, especially through their postgraduate studies and research.

Email: T.L.Riley@massey.ac.nz

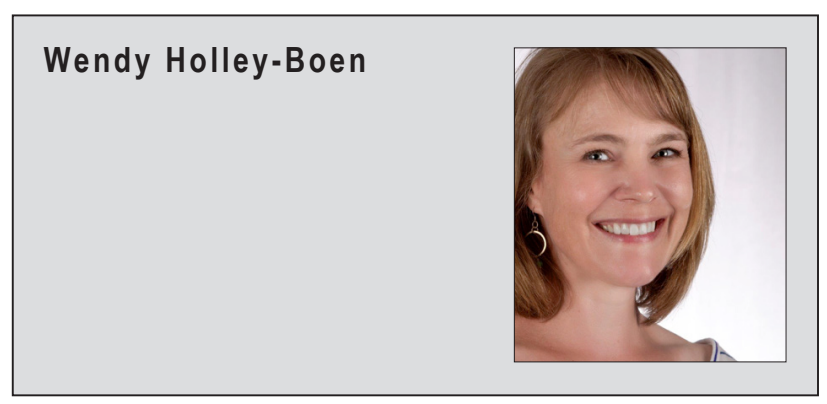

Wendy Holley-Boen has been a registered educational psychologist for nineteen years, and works as a lecturer on the Specialist Teaching Programme at Massey University. Her interests include ecological and interprofessional practice, professional identity, wellbeing, and mentoring.

Email: W.Holley-Boen@massey.ac.nz 